THE KURUME MEDICAL JOURNAL Vol. 11, No. 1, 1964

\title{
CLINICAL OBSERVATION ON SPONTANEOUS CORRECTION OF FRACTURE OF THE SHAFT OF GROWING LONG BONES.
}

\author{
SEIKEI MIYAGI AND TSUKASA MURAYAMA \\ Department of Orthopedic Surgery, Kurume University School of Medicine, \\ Kurume, Japan
}

(Received for Publication February 20, 1964)

It is well-known, that infants have strong capabilities for repairing fractures. Unlike mature bones, regeneration and repair are much stronger and faster in growing bones. Fractured bones healed with some deformities, such as shortening, lateral and bending displacement, will eventually be remodelled to almost perfect condition within several years after fracture.

Many reports have been made in regard to longitudinal growth of fractured bones and remodelling of deformities, but, very few have gone into details to analyze the factors which are believed to be related to the above, such as age, time elapsed, and location, type and displacement of fracture.

The actual length of fractured shafts of growing long bones was measured on patients treated at the Department of Orthopedic Surgery, Kurume University School of Medicine, utilizing scanography as reported by Dr. Inoue of this department. Research was conducted on the relationship between the change of longitudinal growth and the above mentioned factors. Observations were further made on the condition of spontaneous correction of displacement and deformities after the treatment. The results obtained are as follows:

The object of the survey:

The fractured shafts of long bones in patients under 15 years of age were surveyed in 114 cases, including 63 femurs, 54 tibiae, 6 humeri and 18 forearms. The average age of the patients at the time of injury was 6.1 years, and the average time elapsed after injury was 5.7 years. (Table 1 ).

TABLE 1.

\begin{tabular}{l|c|c|c}
\hline \multicolumn{1}{c|}{ Bone } & No. of fractures & Average age at injury & Average years elapsed \\
\hline Femur & 36 & 9.5 & 5.4 \\
Tibia & 54 & 6.1 & 6.2 \\
Humerus & 6 & 1.6 & 5.8 \\
Forearm & 18 & 6.7 & 4.9 \\
\hline Total & 114 & 6.1 & 5.7 \\
\hline
\end{tabular}


The results of the survey:

I. Longitudinal Growth:

The change of longitudinal growth can be generally classified as follows: cases that produced acceleration of growth, and cases in which there was retardation of growth. Acceleration of growth was noticed in 30 (83\%) of 36 femurs, $34(62.9 \%)$ of 54 tibiae, $3(50 \%)$ of 6 humeri, and $37.5 \%$ of radius and $31.2 \%$ of ulnae. Retardation of growth was seen in $3(8.3 \%)$ of the femur, and $1(6.3 \%)$ of the tibiae. Retardation noticed in the radius wag slight, but on the contrary, was very high in the ulnae, one third of the total, or 5 cases $(31.2 \%$ ) (Tabl 2).

TABLE 2.

Change of Length of Bone

\begin{tabular}{l|c|c|c|c|c}
\hline \multicolumn{1}{c|}{ Bone } & Femur & Tibia & Humerus & \multicolumn{2}{|c}{ Forearm } \\
\cline { 3 - 5 } Change & & & & Ulna & Radius \\
\hline Acceleration & $30(83.3) *$ & $34(62.9)$ & $3(50.0)$ & $5(31.2)$ & $6(37.5)$ \\
No change & $3(8.3)$ & $13(24.1)$ & $2(33.3)$ & $6(37.5)$ & $9(56.2)$ \\
Retardation & $3(8.3)$ & $7(13.0)$ & $1(16.7)$ & $5(31.2)$ & $1(6.3)$ \\
\hline
\end{tabular}

* ( ) means $\%$

Further, precise observation made on the extent of the longitudinal growth revealed that $12(33.3 \%)$ of the femurs, and $10(18.5 \%)$ of the tibiae had excessive acceleration of growth; the greatest acceleration was $21 \mathrm{~mm}$ in the femurs and 16.5

TABLE 3.

Details of Changes of Longitudinal Growth

\begin{tabular}{|c|c|c|c|c|c|}
\hline \multirow[b]{2}{*}{ Change } & \multirow{2}{*}{ Femur } & \multirow{2}{*}{ Tibia } & \multirow{2}{*}{ Humerus } & \multicolumn{2}{|c|}{ Forearm } \\
\hline & & & & Ulna & Radius \\
\hline$+++(10 m m \sim)$ & 12 & 10 & 0 & 0 & 0 \\
\hline$++\quad(5 m m \sim 9)$ & 10 & 13 & 2 & 1 & 1 \\
\hline$+\quad(2.5 \sim 4.5 \mathrm{~mm})$ & 8 & 11 & 1 & 4 & 5 \\
\hline$+-\quad(+2 \sim-2 m m)$ & 3 & 13 & 2 & 6 & 9 \\
\hline$-\quad(-2.5 \sim-4.5 \mathrm{mil})$ & 1 & 5 & 0 & 4 & 0 \\
\hline$--(-5 \sim-9.5 \mathrm{~mm})$ & 2 & 2 & 1 & 1 & 1 \\
\hline Total & 36 & 54 & 6 & 16 & 16 \\
\hline
\end{tabular}


$\mathrm{mm}$ in the tibiae. Contrary to the above, acceleration of growth was less than 10 $\mathrm{mm}$ in the humeri and the forearms. Retardation of growth was less than $10 \mathrm{~mm}$ in all cases (Table 3).

1. The relationship between the age of patients and longitudinal growth:

As shown in Tables 4 and 5, excessive over-growth of fractured lower limbs was noticed mainly between the ages of 3 and 10 years. This tendency was particularly noticed in the femur, i.e., the 12 cases which indicated overgrowth exceeding $10 \mathrm{~mm}$ were all between 3 and 10 years old, with the exception of one case which was noticed in a patient over 10 years of age. The rate of over-growth was noticed to be slightly lower in infants under 3 years of age, and many cases over 11 years showed a minor degree of over-growth. Although there were only a few cases, it is believed that the same tendency also existed the upper limbs.

TABLE 4.

Relationship between Age at Injury and Longitudinal Growth (Femur)

\begin{tabular}{c|c|c|c|c|c}
\hline Change Age & $\sim 3$ & $3 \sim 5$ & $5 \sim 7$ & $7 \sim 10$ & $10 \sim$ \\
\hline+++ & 0 & 3 & 4 & 4 & 1 \\
++ & 2 & 5 & 1 & 1 & 1 \\
+ & 2 & 2 & 0 & 0 & 4 \\
+- & 0 & 0 & 1 & 0 & 2 \\
- & 0 & 0 & 1 & 0 & 0 \\
-- & 1 & 0 & 0 & 0 & 1 \\
\hline
\end{tabular}

TABLE 5

Relationship between Age at Injury and Longitudinal Growth (Tibia)

\begin{tabular}{c|c|c|c|c|c}
\hline Change Age & $\sim 3$ & $3 \sim 5$ & $5 \sim 7$ & $7 \sim 10$ & $10 \sim$ \\
\hline+++ & 1 & 5 & 0 & 3 & 1 \\
++ & 0 & 7 & 2 & 3 & 1 \\
+ & 0 & 5 & 4 & 1 & 1 \\
-+ & 0 & 6 & 2 & 2 & 3 \\
- & 2 & 3 & 0 & 0 & 2 \\
-- & 0 & 0 & 0 & 0 & 0 \\
\hline
\end{tabular}

2. The relationship between the location of fracture and longitudinal growth:

Observation was made on the location of fracture by dividing the bone area into three sections, namely, proximal, middle and distal. 
Femur:

Over-growth was noticed in $9(82 \%)$ of the 11 caes of the proximal section, and $3(27 \%)$ of these cases indicated overgrowth of more than $10 \mathrm{~mm}$; and one of the remaining 2 cases showed no change and the other showed retardation of growth. Over-growth was noticed in $15(79 \%)$ of the 19 cases of the middle section, among which 5 (26\%) indicated over-growth of more than $10 \mathrm{~mm}$; and among the remaining 4 cases, 2 showed no chage and the other 2 showed retardation. Finally, all 6 cases of the distal section showed over-growth and 4 of them indicated an over-growth of more than $10 \mathrm{~mm}$. These facts show that over-growth is most remarkable in the distal section (Table 6).

TABLE 6

Relationship between Location of Fracture and Longitudinal Growth

\begin{tabular}{c|c|c|c|c|c|c}
\hline \multirow{2}{*}{ Location } & \multicolumn{3}{|c|}{ Femur } & \multicolumn{3}{c}{ Tibia } \\
\cline { 2 - 6 } Change & Proximal & Middle & Disial & Proximal & Middle & Distal \\
\hline Acceleration & 9 & 15 & 6 & 3 & 9 & 20 \\
No change & 1 & 2 & 0 & 0 & 1 & 12 \\
Retardation & 1 & 2 & 0 & 0 & 1 & 6 \\
\hline
\end{tabular}

Tibiae:

Over-growth was seen in all of the 3 cases of the proximal section and 9 (82\%) of the 11 cases of the middle section showed over-growth; but over-growth was very low in the cases of the distal section, a percentage of $53 \%$ or 20 cases among 38 case. Further, 6 cases (16\%) of the distal section showed retardation of growth, and in some of them, the fractures had extended to the epiphyseal plate (Table 6).

Humeri:

Among 6 cases, over-growth was noticed in one case of each the proximal and the distal sections; and in each case of the middle section over-growth and retardation were noticed, and the remaining two cases showed no change (Table 7).

TABLE 7.

Relationship between Location of Fracture and Longitudinal Growth

\begin{tabular}{c|c|c|c|c|c|c}
\hline \multirow{2}{*}{ Location } & \multicolumn{3}{|c|}{ Humerus } & \multicolumn{3}{c}{ Forearm } \\
\cline { 2 - 7 } Change & Proximal & Middle & Distal & Praximal & Middle & Distal \\
\hline Accelaration & 1 & 1 & 1 & 0 & 4 & 7 \\
No change & 0 & 2 & 0 & 1 & 10 & 4 \\
Retardation & 0 & 1 & 0 & 0 & 4 & 1 \\
\hline
\end{tabular}


Forearms:

Among 31 cases of fractures of the forearm, 15 cases showed no change, and over-growth was noticed in $4(22 \%)$ of 18 cases of the middle section and in $7(58 \%)$ of 12 cases of the distal section, showing a comparatively high rate of over-growth in the latter group (Table 7).

As shown above, in regard to the relationship between the location of fracture and the change of longitudinal growth, greater acceleration was noticed in fractures located near the metaphysis than in the diaphysis.

3. The relationship between the type of fracture and longitudinal growth:

A study was conducted on the change of growth by dividing the types of fractures into two groups, namely, transverse fracture and oblique fracture (Table 8).

TABLE $\quad 8$.

Relationship between Type of Fracture and Longitudinal Growth

\begin{tabular}{c|c|c|c|c}
\hline \multirow{2}{*}{ Type } & \multicolumn{2}{|c|}{ Femur } & \multicolumn{2}{c}{ Tibia } \\
\cline { 2 - 5 } Change & Oblique & Transverse & Oblique & Transverse \\
\hline Acceleration & 18 & 12 & 8 & 19 \\
No change & 2 & 1 & 1 & 7 \\
Retardation & 2 & 1 & 0 & 4 \\
\hline
\end{tabular}

\section{Femurs:}

Observation was made on 22 cases of transverse fracture, and $18(86 \%)$ of these cases were found to have accelerated growth, $7(36 \%)$ of which showed an overgrowth of more than $10 \mathrm{~mm}$. Further, in oblique fractures, $12(86 \%)$ of the 14 cases showed acceleration, 5 cases (36\%) of which showed an over-growth more than 10 $\mathrm{mm}$. This proves that the rate of acceleration of growth is greater in the oblique than in the transverse fractures.

Tibiae:

Over-growth was noticed in $8(89 \%)$ of the 9 transverse fractures, and $19(63 \%)$ of the oblique fractures, which indicates that the rate of acceleration is much lower in the latter than in the former. Concerning over-growth of more than $10 \mathrm{~mm}, 2$ cases $(22 \%)$ were noticed in the transverse, and 8 cases $(27 \%)$ in the oblique fractures. Four cases of oblique fracture showed retardation, and these cases were located in the distal section of the tibiae, in which the fracture extended from the metaphysis to the epiphyseal plate.

Humeri and forearms:

The majority of cases invloved were that of transverse fractures, and their comparison with oblique fractures was unable to be made. However, generally, it seems that a significant difference in change of longitudinal growth cannot be recognized by the type of fracture.

4. The relationship between displacement and longitudinal growth: 
In regard to shortening and lateral displacement, X-ray photographs taken at the time of union or at the end of treatment were utilized in observing the degree of displacement and the change of longitudinal growth.

Femurs:

Among 17 cases of femoral fracture with displacement, $13(76.4 \%)$ indicated acceleration, of which $4(23.5 \%)$ indicated acceleration of more than $10 \mathrm{~mm}$ and 9 (52.9\%) less than $10 \mathrm{~mm}$; and in the remaining 2 cases, one case showed no change and the other showed retardation. Four cases whith an over-growth of more than 10 $\mathrm{mm}$ were found after operative treatment. Among 12 cases having a shortening of less than $10 \mathrm{~mm}, 10$ cases (83.3\%) showed accelerated more than $10 \mathrm{~mm}$, and $10(50$ \%) less than $10 \mathrm{~mm}$. Among 6 cases with a shortening of more than $10 \mathrm{~mm}$, all cases indicated acceleration of growth, of which 4 cases $(66.7 \%)$ indicated a high rate of more than $10 \mathrm{~mm}$. Other than the above cases, there was a case which had united with $5 \mathrm{~mm}$. of over-traction, resulting in an over-growth of $7 \mathrm{~mm}$., and therefore, in a length $12 \mathrm{~mm}$ in excess of that of the other limb.

TABLE 9.

Relationship between Dislocation and Longitudinal Growth (Femur)

\begin{tabular}{c|c|c|c|c|c|c}
\hline \multirow{2}{*}{ Dislocation } & \multicolumn{3}{|c|}{ Shortening } & \multicolumn{3}{|c}{ Lateral } \\
\cline { 2 - 6 } Change & No & $\begin{array}{l}\text { Within } \\
10 \mathrm{~mm}\end{array}$ & $\begin{array}{l}\text { Over } \\
10 \mathrm{~mm}\end{array}$ & No & $\begin{array}{l}\text { Within a } \\
\text { width of } \\
\text { diaph. }\end{array}$ & $\begin{array}{l}\text { Over a } \\
\text { width of } \\
\text { diaph. }\end{array}$ \\
\hline+++ & 4 & 4 & 4 & 4 & 5 & 3 \\
++ & 4 & 3 & 2 & 1 & 7 & 2 \\
+- & 5 & 3 & 0 & 4 & 2 & 0 \\
- & 2 & 1 & 0 & 1 & 2 & 0 \\
\hline
\end{tabular}

In regard to lateral displacement, $9(75 \%)$ of 12 cases with no displacement indicated acceleration of gowth, of which 4 cases (33.3\%) had an over-growth of more than $10 \mathrm{~mm}$ and they all had been treated by operative reduction. In the remaining cases, one cases showed medium acceleration $(5 \sim 9.5 \mathrm{~cm}), 4$ cases slight acceleration $(2.5 \sim 4.5 \mathrm{~mm}), 1$ case no change, and 2 cases showed retardation. Among 16 cases with lateral displacement within the width of diaphysis, 14 cases $(87.7 \%)$ indicated acceleration, of which 7 cases $(43.8 \%)$ showed medium, 5 cases $(31.3 \%)$ high, and 2 cases little acceleration; and the remaining cases showed no change. Acceleration was noticed in 7 cases (87.5) of 8 cases with lateral displacement over the width of diaphysis, of which 3 showed high, 2 medium and 2 slight acceleration. The one case which retardation was that of a 3 year old boy at the time of fracture, followed by a shortening of $6 \mathrm{~mm} 9$ years later (Table 9).

Tibiae:

Among 34 cases with no shortening, 17 cases (50\%) showed acceleration, of which 
only 3 cases (9\%) showed an over-growth of more than $10 \mathrm{~mm}$, and the majority were less than $10 \mathrm{~mm}$. The other 11 cases showed no change, and 6 cases (17.6\%) showed retardation. Among 14 cases with less than $10 \mathrm{~mm}$ shortening acceleration was seen in 11 cases $(78.6 \%)$, and there were as many as 5 cases $(35.7 \%)$ with an over-growth of more than $10 \mathrm{~mm}$. There were only 3 cases of no change and retardation. Two cases with more than $10 \mathrm{~mm}$ shortening were noticed to have an over-growth of more than $10 \mathrm{~mm}$.

TABLE 10.

Relationship beiween Dislocation and Longitudinal Growth (Tibia)

\begin{tabular}{c|c|c|c|c|c|c}
\hline \multirow{2}{*}{ Dislocation } & \multicolumn{3}{|c|}{ Shortening } & \multicolumn{3}{c}{ Lateral } \\
\cline { 2 - 7 } Change & No & $\begin{array}{l}\text { Within } \\
10 \mathrm{~mm}\end{array}$ & $\begin{array}{l}\text { Over } \\
10 \mathrm{~mm}\end{array}$ & No & $\begin{array}{l}\text { Within a } \\
\text { width of } \\
\text { diaph. }\end{array}$ & $\begin{array}{l}\text { Over a } \\
\text { width of } \\
\text { diaph. }\end{array}$ \\
\hline+++ & 3 & 5 & 2 & 1 & 9 & 0 \\
++ & 7 & 4 & 0 & 5 & 6 & 0 \\
+- & 7 & 2 & 0 & 6 & 4 & 0 \\
- & 11 & 2 & 0 & 6 & 7 & 0 \\
\hline
\end{tabular}

Concerning lateral displacement, over-growth was noticed in 17 cases (5\%) of 34 cases with no displacement, and there was only one case with an over-growth of more than $10 \mathrm{~mm}$. Among 27 cases with lateral displacement within the width of the diaphysis, over-growth was noticed in 19 cases (70.4\%), of which 9 cases $(33.3 \%)$ were noticed to have accelerated more than $10 \mathrm{~mm}$ (Table 10).

Humeri:

Acceleration of longitudinal growth was noticed in two cases of the humeri, one having a shortening of less than $10 \mathrm{~mm}$, and the other a lateral displacement over the width of the diaphysis (Table 11).

TABLE 11.

Relationship between Dislocation and Longitudinal Growth (Humerus)

\begin{tabular}{|c|c|c|c|c|}
\hline \multirow[b]{2}{*}{ Change } & \multicolumn{2}{|c|}{ Shoriening } & \multicolumn{2}{|c|}{ Lateral } \\
\hline & Absent & Present & Absent & Present \\
\hline Acceleration & 1 & 2 & 0 & 2 \\
\hline No change & 2 & 0 & 2 & 1 \\
\hline Retardation & 1 & 0 & 1 & 0 \\
\hline
\end{tabular}


Forearms:

Acceleration of growth was noticed in 7 cases (36.8\%) among 19 cases without shortening, and in 4 cases $(44.4 \%)$ of 9 cases with shortening. Acceleration of growth was noticed in 5 cases $(29.4 \%)$ of 17 cases without lateral displacement, and 6 cases (54.5\%) of 11 cases with displacements (Table 12).

TABLE 12.

Relationship between Dislocaíion and Longitudinal Growih (Forearm)

\begin{tabular}{|c|c|c|c|c|}
\hline \multirow[b]{2}{*}{ Change } & \multicolumn{2}{|c|}{ Shortening } & \multicolumn{2}{|c|}{ Lateral } \\
\hline & Absent & Present & Absen & Present \\
\hline Acceleration & 7 & 4 & 5 & 6 \\
\hline No change & 7 & 5 & 8 & 4 \\
\hline Reíardation & 5 & 0 & 4 & 1 \\
\hline
\end{tabular}

As shown abo e, a higher rate of acceleration of growth was noticed in fractured bones which had healed with displacements remaining. Also, many cases were noticed to have excessive over-growth where the degree of displaccment was greater.

5. Elapse of time and change of longitudinal growth;

Observation was made on the relationship between the change of longitudinal growth and the elapse of time after the fracture. It was noticed that there were no significant change in those, in which the period was less than a year, and a higher rate of over-growth was seen in those over a year. This over-growth was noticed to have continued even after 10 or more years (Table 13 \& 14). Further, a 2nd check, 5 years after the lst, was made on 15 cases ( 5 femur and 10 tibiae) in order to observe their growth conditions, and acceleration of longitudinal growth was seen in many of the cases at the 2nd check (Table 15). Taking the above facts into consideration,

TABLE 13.

Relationship beiween Yexrs Elapsed and Longitudinal Growih (Fimur)

\begin{tabular}{c|c|c|c|c|c|c}
\hline Years & $\sim 2$ & $2 \sim 3$ & $3 \sim 5$ & $5 \sim 7$ & $7 \sim 10$ & $10 \sim$ \\
+++ & 3 & 1 & 3 & 2 & 2 & 1 \\
++ & 1 & 0 & 2 & 3 & 3 & 1 \\
+ & 2 & 1 & 1 & 2 & 1 & 1 \\
+- & 1 & 1 & 0 & 1 & 0 & 0 \\
- & 0 & 0 & 0 & 0 & 0 & 1 \\
-- & 0 & 0 & 0 & 1 & 1 & 0 \\
\hline
\end{tabular}


TABLE 14

Relationship between Years Elapsed and Longitudinal Gowth (Tibia)

\begin{tabular}{|c|c|c|c|c|c|c|}
\hline Change Years & $\sim 2$ & $2 \sim 3$ & $3 \sim 5$ & $5 \sim 7$ & $7 \sim 10$ & $10 \sim$ \\
\hline+++ & 0 & 0 & 2 & 1 & 3 & 4 \\
\hline++ & 1 & 0 & 5 & 2 & 4 & 1 \\
\hline+ & 0 & 4 & 2 & 2 & 2 & 1 \\
\hline+- & 4 & 1 & 2 & 1 & 4 & 1 \\
\hline- & 0 & 0 & 3 & 0 & 0 & 2 \\
\hline-- & 1 & 0 & 0 & 0 & 1 & 0 \\
\hline
\end{tabular}

TABLE 15.

Developmental Change of Length at the 1st and and Check

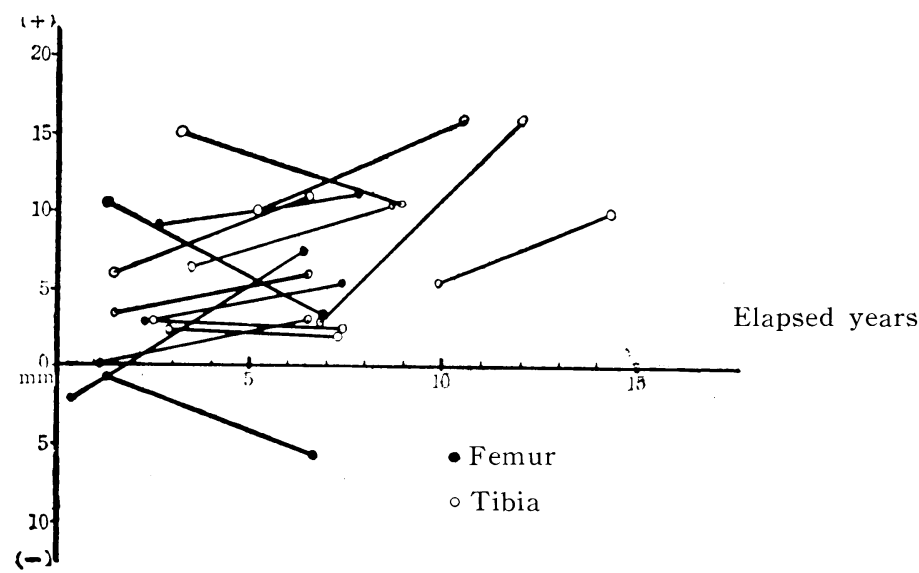

it can be assumed that the stimulation of growth continues for quite a while after the fracture. and it is believed that over-growth is high during the period between one and three years after the fracture and it continues for several years thereafter.

6. Change of longitudinal growth in fractured bone and its effect on the adjacent bone:

Observation was made on the changes of longitudinal growth in both the femur and tibia. Observing the change of the tibia in relation to the fractured femur, it was noticed that $12(33.3 \%)$ of 36 tibiae showed acceleration of longitudinal growth, $16(44.4 \%)$ showed no change, and $36(22.2 \%)$ showed retardation. Among the 12 cases that produced excessive over-growth of more than $10 \mathrm{~mm}$ in the fractured femur, it was recognized that there were 5 cases $(41.7 \%)$ with over-growth of the tibia, and 2 cases $(16.7 \%)$ with retardation of growth. Over-growth was recognized also in the tibiae in all of the 3 fractured femurs with retardation of growth (Table 16). 
TABLE 16.

Relationship between the Length of the Femur and that of the Tibia in the Fractured Femur

\begin{tabular}{|c|c|c|c|c|c|c|}
\hline Femur $\quad$ Tibia & +++ & ++ & + & +- & - & -- \\
\hline+++ & 0 & 4 & 1 & 5 & 1 & 1 \\
\hline++ & 0 & 0 & 1 & 7 & 2 & 0 \\
\hline+ & 0 & 1 & 2 & 2 & 1 & 2 \\
\hline+- & 0 & 0 & 0 & 2 & 0 & 1 \\
\hline- & 0 & 1 & 0 & 0 & 0 & 0 \\
\hline-- & 0 & 0 & 2 & 0 & 0 & 0 \\
\hline
\end{tabular}

Over-growth of the femur was recognized in 16 cases (30.8\%) of 52 fractured tibiae, no chage in 23 cases (44.2\%), and retardation in 13 cases (25\%). This tendency is believed to be approximately the same as that of the cases with femoral fractures. Among 6 cases with retardation of growth in fractured tibiae. both acceleration and retardation were seen in 3 femurs (Table 17).

TABLE 17.

Relationship between the Length of the Femur and That of the Tibia in the Fractured Tibia

\begin{tabular}{|c|c|c|c|c|c|c|}
\hline Femur Tibia & +++ & ++ & + & +- & - & -- \\
\hline+++ & 0 & 3 & 0 & 5 & 2 & 0 \\
\hline++ & 1 & 2 & 1 & 4 & 5 & 0 \\
\hline+ & 1 & 2 & 0 & 6 & 2 & 0 \\
\hline+- & 0 & 2 & 1 & 8 & 0 & 1 \\
\hline- & 1 & 0 & 1 & 0 & 1 & 2 \\
\hline-- & 0 & 0 & 1 & 0 & 0 & 0 \\
\hline
\end{tabular}

7. The relationship between the operation and the over-growth of fractured bones:

Table 18 shows the change of longitudinal growth in the cases of operated fractures.

Comparing the operated and non-operated cases with an excessive over-growth of more than $10 \mathrm{~mm}$ in the fractured femur, cases of over-growth were noticed to be a little higher in the operated cases, namely, 5 cases $(38.4 \%)$ of 13 operated cases and 7 cases $(30.4 \%)$ of 23 non-operated cases (Table 19). 
TABLE 18.

Effect of the Operation on Longitudinal Growth

\begin{tabular}{|c|c|c|c|c|}
\hline Change Bone & Femur & Tibia & Forearm & Total \\
\hline+++ & 5 & 1 & 0 & 6 \\
\hline++ & 3 & 0 & 0 & 3 \\
\hline+ & 3 & 1 & 1 & 5 \\
\hline+- & 1 & 0 & 1 & 2 \\
\hline- & 1 & 0 & 0 & 1 \\
\hline Total & 13 & 2 & 2 & 17 \\
\hline
\end{tabular}

TABLE 19

Acceleration of Longitudinal Growth According to the Method of Treatment

\begin{tabular}{l|c|c}
\hline Method & No. Cases & $\begin{array}{l}\text { Over growth } \\
\text { over 10 } \mathrm{mm}\end{array}$ \\
\hline Operative & 13 & $5(38.4 \%)$ \\
Conservative & 23 & $7(30.4 \%)$ \\
\hline
\end{tabular}

II . Spontaneous correction of displacement:

Observation was made on the spontaneous correction of the lateral and the bending displacement, comparing the X-ray findings at the end of the treatment with those at survey, care was taken in operating the X-ray camera in order to take the photographs in the same position.

1. Spontaneous correction of lateral displacement.

Femur:

In the fractured femurs with lateral displacement within $1 / 2$ width of the diaphysis, the bone marrow connected almost completely after a year or so, showing a slight thickening of the cortex, and the remodelling was completed after an elapse of 3 or 4 years. Although thickening of the cortex and a slight deformity were noticed even after a year in many cases with lateral displacement from $1 / 2$ to a width of the diaphysis, the fractured femurs recovered almost to their original shapes after an elapse of 3 or 4 years (Fig. 1).

In cases with a lateral displacement of a width or more of the diaphysis, the callus abundantly produced around the fracture sites decreased in size after one or 2 years, being absorbed from their convex sites and connected the proximal and distal fragments in slightly declining curves.

The bone marrow of both fragments had already begun to connect with each other (Fig. 2). Generally, after 5 years, the longitudinal axis of the proximal and distal 
Fig. 1.

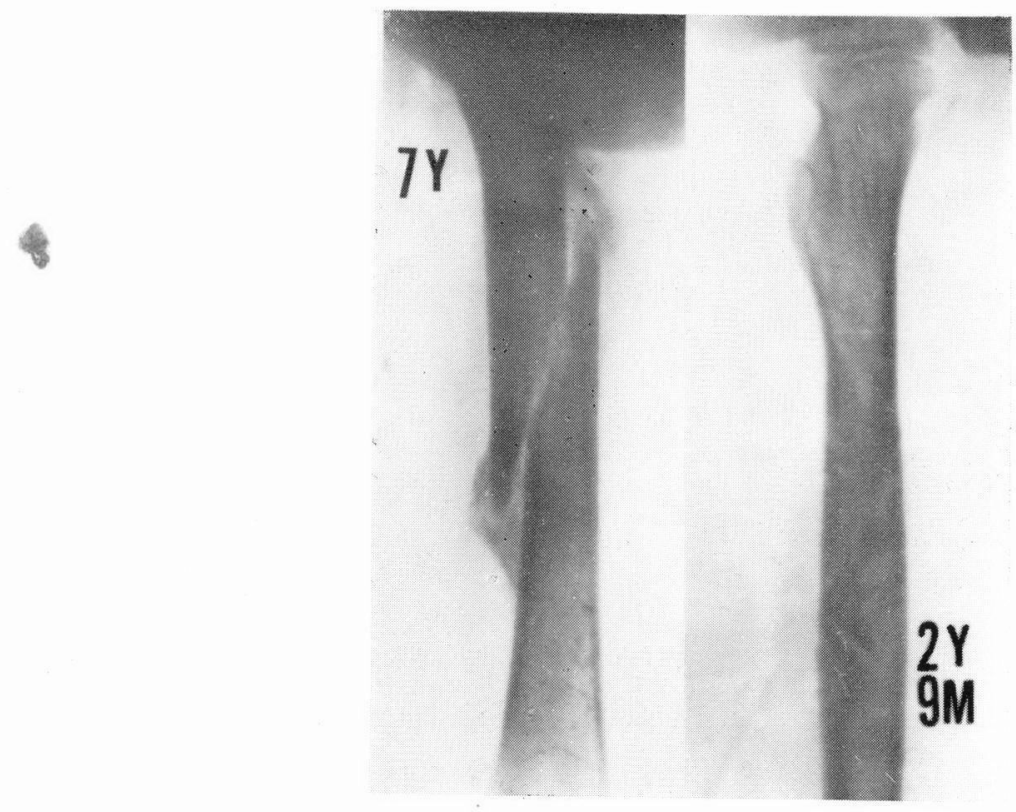

Number of the left above shows years and months of age at the time $\mathrm{cf}$ fracture and that of the right below shows years and months elapsed

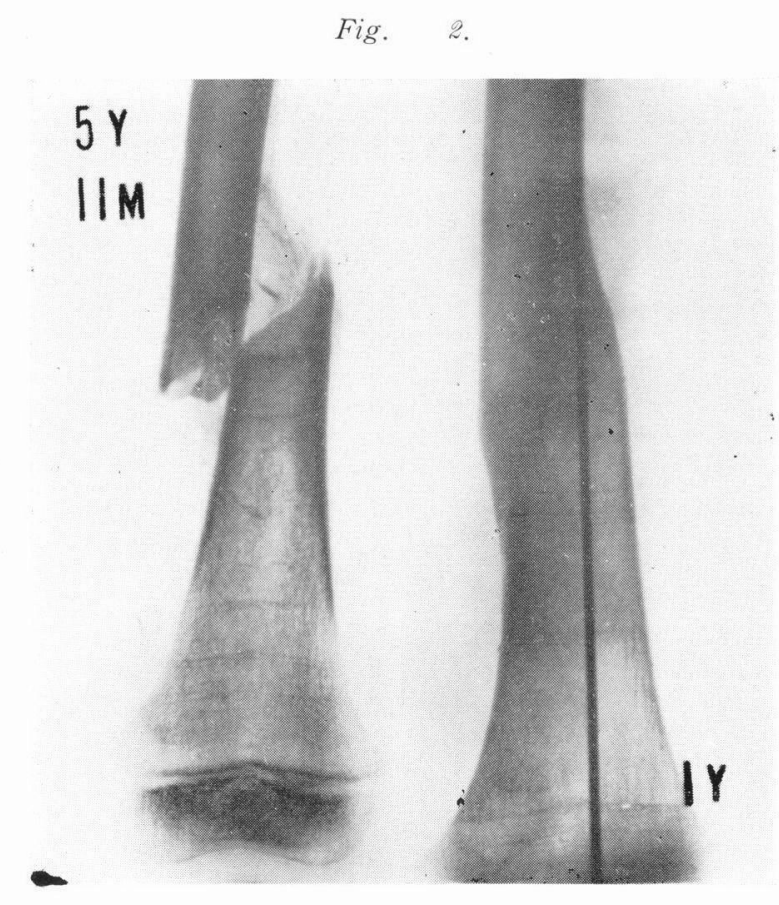


fragments had been aligned, leaving a trace of the displacement. Further, almost complete remodelling was noticed in cases, in which 8 or more years had elapsed (Fig. 3, 4 \& 5).

$$
\text { Fig. 3. }
$$

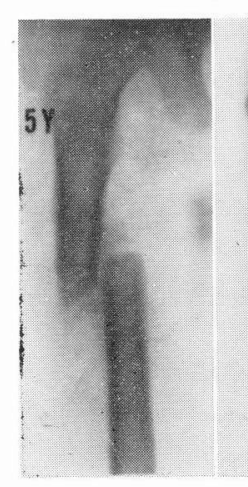

Fig. 4.

Fig. 5 .

Tibiae:

No case with displacement of more than $1 / 2$ width of the diaphysis was noticed in this series of the survey. Among the cases with displacement of approximately $1 / 2$ width of the diaphysis, many cases were noticed to have nearly recovered their original shapes within a year or two. Among the older children, though some deformities remained, complete remodelling was noticed after 3 or 4 years (Fig. 6, $7 \& 8)$.

Fig. 6 .

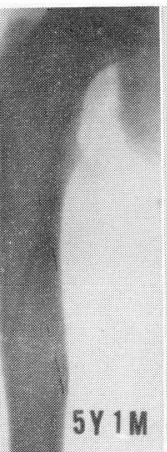

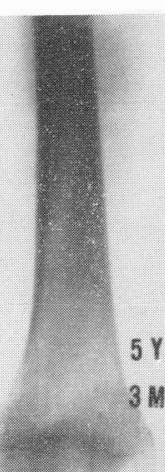

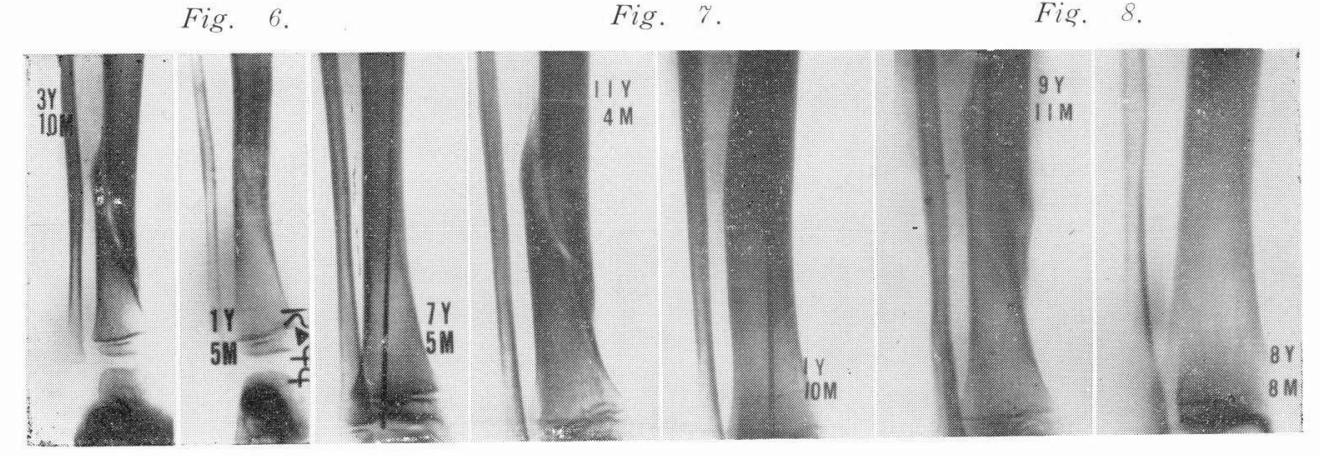

Humeri:

One case with dislacement of $3 / 4$ width of the diaphysis had almost completed its remodelling 14 months after the fracture (Fig. 9).

The remodelling of two cases with displacment of a width of the diaphysis was completed at the time of survey, which was 6 and 8 years after the fractures.

Forearms:

Cases with displacement of $1 / 2$ width of the diaphysis had completed remodelling within 2 years, and correction of one case with displacement of a width of the diaphysis was completed within 5 years after the fracture (Fig. 10). 


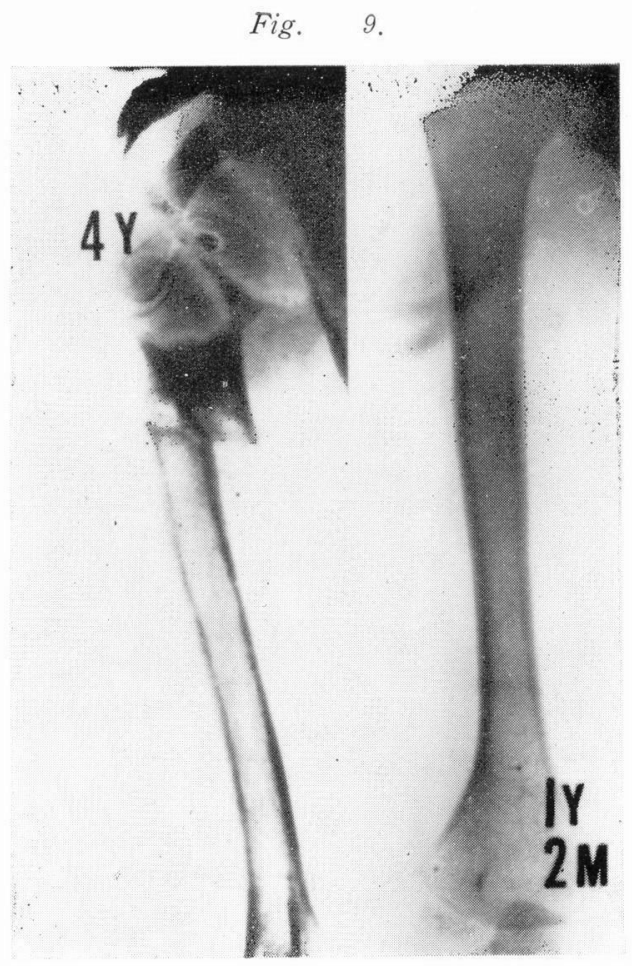

Fig. $\quad 10$.

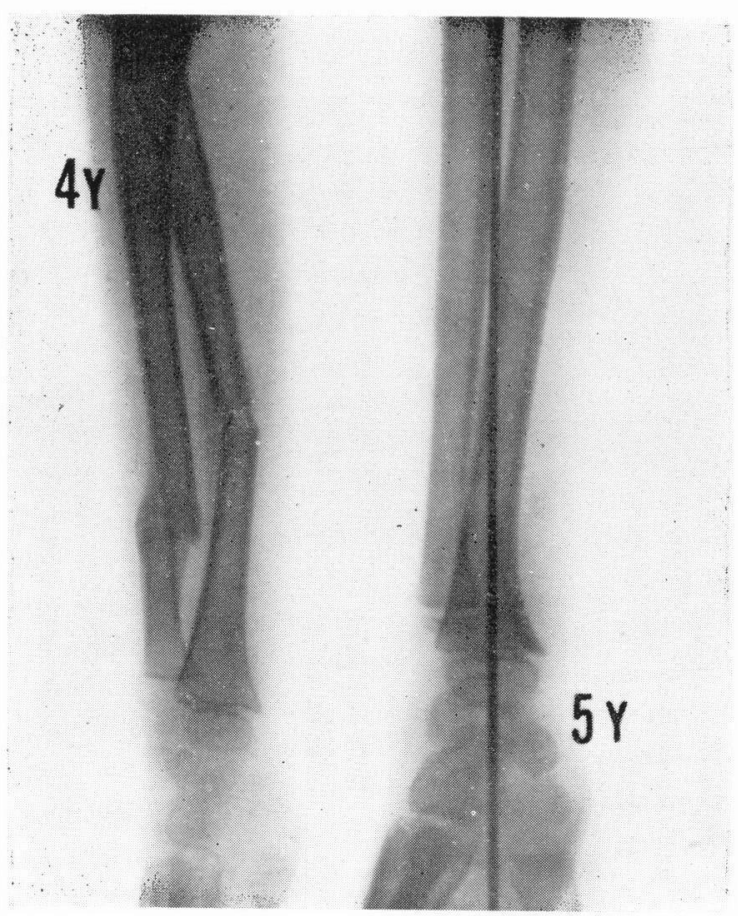


The above facts indicate that the fractured femurs and tibiae have a strong capability of correction of the lateral displacement, and the progress of the remodelling is very rapid. Further, in cases where comparatively great displacement existed, sufficient remodelling was made within a few years. In cases of fractured humeri and forearms, the capability of correction of the lateral displacement was slightly lower than the above. The faster progress of remodelling was noticed to be during the lst and 2nd years after the union of the fractures, which gradually slowed down as the years elapsed. However, it is believed that remodelling continued during the growth of bone.

It has been recognized that, generally, remodelling of fractured bones will be completed within several years after the fracture in cases with displacement of a width of the diaphysis in the femurs and tibiae, and $1 / 2$ width of the diaphysis in the forearms and humeri.

2. Spontaneous correction of bending displacement:

A survey was conducted on the correction of the bending displacement over 10 degrees, as shown in Table 20.

TABLE 20.

Remodelling of the Bending Displacement

\begin{tabular}{|c|c|c|c|c|c|c|c|c|}
\hline Case & Sex. & $\begin{array}{l}\text { Age at } \\
\text { injury }\end{array}$ & $\begin{array}{l}\text { Lacation } \\
\text { of f*acture }\end{array}$ & $\begin{array}{l}\text { Elapsed } \\
\text { years }\end{array}$ & $\begin{array}{l}\text { Angle } \\
\text { at union }\end{array}$ & $\begin{array}{l}\text { Angle } \\
\text { at survey }\end{array}$ & $\begin{array}{l}\text { Angle of } \\
\text { correction }\end{array}$ & $\begin{array}{c}\text { Rate of } \\
\text { correction } \\
(\%)\end{array}$ \\
\hline 1 & M. & $1 \mathrm{M}$. & Femur. mid, & $9 \mathrm{Y} .8 \mathrm{M}$ & $29^{\circ}$ & $8^{\circ}$ & $21^{\circ}$ & 72 \\
\hline 2 & M. & $8 \mathrm{Y}$. & Femur. prox. & $\begin{array}{llll}1 & \mathrm{Y} . & 4 & \mathrm{M} \\
6 & \mathrm{Y} . & 4 & \mathrm{M}\end{array}$ & $19^{\circ}$ & $11^{\circ}$ & $\begin{array}{r}8^{\circ} \\
14^{\circ}\end{array}$ & $\begin{array}{l}42 \\
74\end{array}$ \\
\hline 3 & $\mathrm{~F}$. & $3 \mathrm{Y}$. & Femur. mid. & $5 \mathrm{Y} .3 \mathrm{M}$. & $14^{\circ}$ & $8^{\circ}$ & $6^{\circ}$ & 43 \\
\hline 4 & $\mathrm{~F}$. & $4 \mathrm{Y}$. & Femur. med. & 4 Y. 3 M. & $12^{\circ}$ & $6^{\circ}$ & 6 & 50 \\
\hline 5 & $\mathrm{~F}$. & $9 \mathrm{M}$. & Femur. dis. & 3 Y. 1 M. & $27^{\circ}$ & $12^{\circ}$ & $15^{\circ}$ & 56 \\
\hline 6 & $\mathrm{~F}$. & $4 \mathrm{Y}$. & Tibia. mid. & $\begin{array}{lll}2 & \text { Y. } & 5 \mathrm{M} . \\
7 & \mathrm{Y} . & 8 \mathrm{M}\end{array}$ & $14^{\circ}$ & $\begin{array}{l}9^{\circ} \\
5^{\circ}\end{array}$ & $\begin{array}{l}5^{\circ} \\
9^{\circ}\end{array}$ & $\begin{array}{l}36 \\
64\end{array}$ \\
\hline 7 & $\mathrm{~F}$. & $6 \mathrm{Y}$. & Tibia. mid. & $\begin{array}{lll}1 & \mathrm{Y} . & \\
6 & \mathrm{Y} . & 5 \mathrm{M} .\end{array}$ & $13^{\circ}$ & $\begin{array}{l}9^{\circ} \\
5^{\circ}\end{array}$ & $\begin{array}{l}4^{\circ} \\
8^{\circ}\end{array}$ & $\begin{array}{l}31 \\
62\end{array}$ \\
\hline 8 & M. & $9 \mathrm{Y}$. & Tibia. dist. & 4 Y. 3 M. & $16^{\circ}$ & $6^{\circ}$ & $10^{\circ}$ & 63 \\
\hline 9 & F. & $11 \mathrm{Y}$. & Tibia. dist. & $1 \mathrm{Y} .9 \mathrm{M}$ & $10^{\circ}$ & $6^{\circ}$ & $4^{\circ}$ & 40 \\
\hline 10 & M. & $3 \mathrm{Y}$ & Fibula. dist. & 7 Y. $6 \mathrm{M}$ & $30^{\circ}$ & $0^{\circ}$ & $30^{\circ}$ & 100 \\
\hline 11 & M. & $3 \mathrm{Y}$. & Fibula. dist. & $3 \mathrm{Y} .1 \mathrm{M}$ & $10^{\circ}$ & $0^{\circ}$ & $10^{\circ}$ & 100 \\
\hline 12 & M. & $9 \mathrm{Y}$. & Ulna. prox. & 7 Y. 2 M. & $30^{\circ}$ & $16^{\circ}$ & $14^{\circ}$ & 47 \\
\hline 13 & M. & $3 \mathrm{Y}$. & Radius. mid. & $6 \mathrm{Y} .10 \mathrm{M}$ & $17^{\circ}$ & $5^{\circ}$ & $12^{\circ}$ & 71 \\
\hline 14 & M. & $9 \mathrm{Y}$ & Radius. mid. & $6 \mathrm{Y} .8 \mathrm{M}$ & $18^{\circ}$ & $10^{\circ}$ & $8^{\circ}$ & 44 \\
\hline 15 & M. & $4 \mathrm{Y}$ & Radius. mid. & $5 \mathrm{Y}$ & $20^{\circ}$ & $3^{\circ}$ & $17^{\circ}$ & 85 \\
\hline 16 & M. & $10 \mathrm{Y}$. & Radius. mid. & $4 \mathrm{Y} .5 \mathrm{M}$ & $17^{\circ}$ & $7^{\circ}$ & 10 & 59 \\
\hline 17 & F. & $1 \mathrm{Y}$ & Ulna. mid. & 3 Y. 9 M. & $14^{\circ}$ & $7^{\circ}$ & 7 & 50 \\
\hline 18 & F. & $3 \mathrm{Y}$. & Radius. dist. & $3 \mathrm{Y}$ & $30^{\circ}$ & $0^{\circ}$ & $30^{\circ}$ & 100 \\
\hline 19 & $\mathrm{~F}$. & $1 \mathrm{Y}$ & Forearm. mid. & $1 \mathrm{Y} .8 \mathrm{M}$ & $40^{\circ}$ & $18^{\circ}$ & $22^{\circ}$ & 45 \\
\hline 20 & $\mathrm{~F}$. & $7 \mathrm{Y}$ & Forearm. dist. & $1 \mathrm{Y} .6 \mathrm{M}$. & $18^{\circ}$ & $0^{\circ}$ & $18^{\circ}$ & 100 \\
\hline
\end{tabular}


Observing each case as shown in Table 20, a femoral fracture with a bending displacement of 29 degrees made a correction of 21 degrees (72\%) within 9 years and 8 months after the fracture. Further, cases having a bending displacement of 19 degrees indicated a correction of 14 degrees (74\%) afte 6 years and 4 months. However, in two cases a correction of 8 degrees (42\%) was already made during the lst year and 4 months. In cases 3,4 and 5, an average correction of $50 \%$ was noticed 3 years later (Fig. 11). A Comparison was made on cases 3 and 4 , which revealed that the former made a correction of 15 degrees on a bending displacement of 27 degrees in the distal fragment, and the latter made a correction of only 6 degrees on bending displacements of 14 and 12 degrees, respectively.

The rate of correction in cases 6,7 and 8 , three fractured tibiae, having a time elapse of over 4 years, was approximately $60 \%$, but cases 10 and 11 with fractured

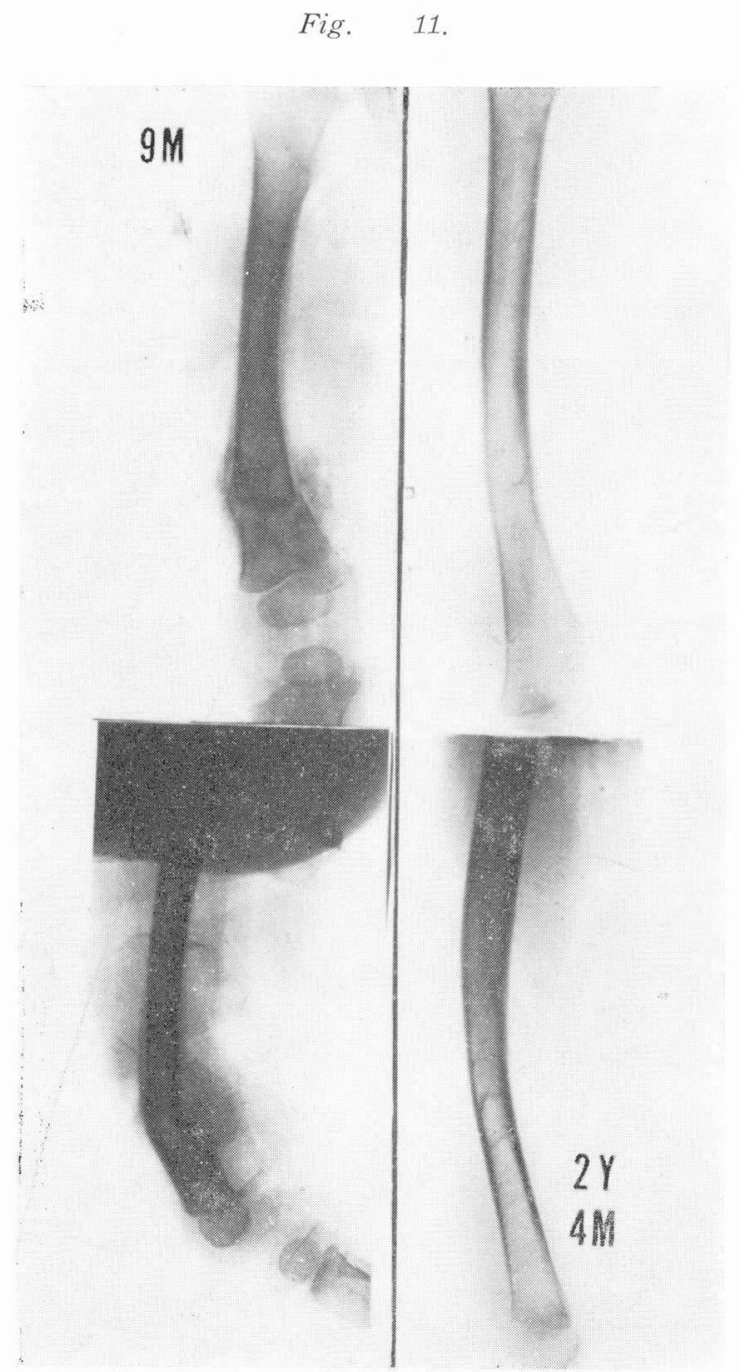




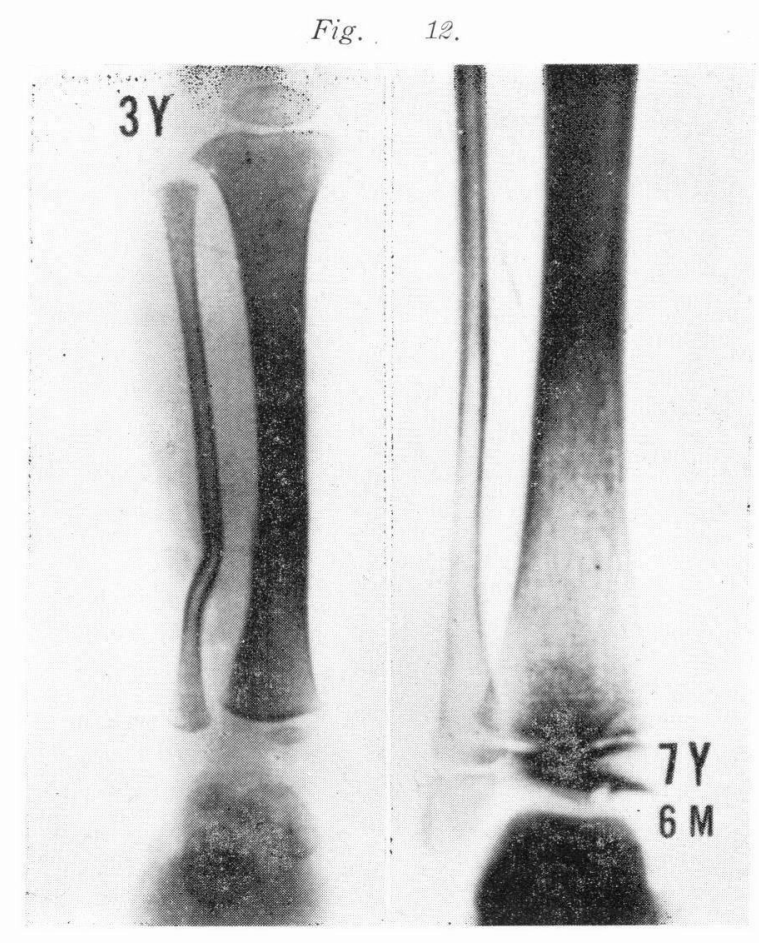

fibula had completed corrections which had bending displacements of 39 and 19 degrees, respectively (Fig. 12).

In regard to the 9 cases with fractured forearms, the 2 cases (cases 18 and 20), having a bending displacement of 30 and 18 degrees, respectively, in the distal fragments, were completely corrected, and 6 cases with fractures in the middle part of the diaphysis had a correction of 7 to 22 degrees at the most or an average correction of $60 \%$. As shown above, corrections are noticed to occur at a higher rate in the distal section than in the middle section of the diaphysis. It can be assumed that the capability of spontaneous correction is greater where the fracture is nearer the metaphysis.

As indicated in cases 2, 6, 7, 19 and 20, the capability of spontaneous correction is greater during the 1st and 2nd years, and its rate gradually decreases as the years elapse. Generally, correction of the bending displacement is greater in the forearms and the fibulae, some reaching up to 30 degrees. In the fractured femurs, a case was noticed to have a correction of 21 degrees, but the majority were below 15 degrees. The rate of correction for the fractured tibia is considered to be less than 10 degrees.

III. Summary and conclusion.

In regard to acceleration in longitudinal growth and spontaneous correction of deformities after fracture of the shaft of growing long bones, an investigation was carried out on 36 femurs, 54 tibiae, 6 humeri and 18 forearms, and the relationships concerned were observed. The average age at the time of injury of the patients studied was 6.1 years and the average time elapsed after injury was 5.7 yeas. 
The results obtained were as follows:

1. In fractures of the shaft of long bones an acceleration of growth occurred more frequently, especially between the ages of 3 and 10 years, and over-growth was outstanding, and seemed to be relatively highly-involved when the fracture was near the metaphysis, provided that the epiphysis did not fuse in the meantime. The overgrowth was little oncerned with the type of fracture, and the larger the displacement the more advanced the over-growth.

Over-growth occurred distinctly during the period of one to three years after injury and persisted afterward. The authors believe that the over-growth which occurred after fracture will remain permanently.

Nevertheless, as the limit of the over-growth was, in general, within $2 \mathrm{~cm}$ in the femur, $1.5 \mathrm{~cm}$ in the tibia and $1 \mathrm{~cm}$ in the humerus and the forearm, respectively, the shortening displacement to this extent did not necessarily need to be corrected by operation.

2. The lateral displacement of a width of the disphysis in the femur and the humerus, and that of $1 / 2$ width of the diaphysis in the tibia and forearm could almost be completely corrected spontaneously within several years.

The bending displacement proved to be corrected by 15 degrees in the femur and the humerus, by 10 degrees in the tibia and by 15 degrees in the forearm, but further investigation should be made on these limits of degrees.

Correction of both the lateral and bending displacement advanced markedly for the first one or two years and then continued slowly.

3. As described above, in fractures of the shaft of growing long bones spontaneous correction took place distinctly and rapidly. There was, therefore, very little, if any, indication for open reduction in patients, especially those under 10 years of age.

\section{REFERENCES}

1. Aitken, A. P. : Overgrowth of femoral shaft following fracture in children. Am. J. Surg. , $49,147,1940$.

2. BrRt, : Über das spätere Schicksale kindlicher Frakturen. Beitr.klin. Chir., 64, 437, 1909.

3. BisqaRd, J. D. : Longitudinal growth of long bones. Arch. surg. , 31, 568, 1935.

4. BrsaARD, J. D. : Longitudinal overgrowth of long bones with special reference to fractures. Surg. Gynec. Obstet. ,62, 823, 1936.

5. Blount, W. P. : Fractures in children. Williams \& Willkins Co., 1954.

6. Brodin, H. : Experimental studies on changed growth in the tibia of rabbits. Acta orthop. scand., 26, 319, 1957.

7. Burdick, C. G. and Siris, I. E. : Fracture in children. Treatment and end results in 268 cases. Ann. Surg., 7\%, 736, 1923.

8. Carpenter, E. B. and Dalton, J. B. : A critical evaluation of a method of epiphysaal stimulation. J. Bone and Joint Surg. , 38, 1089, 1956.

9. Cole, W. H. : Results of treatment of fractured femurs in children with special reference to Bryant's overhead traction. Arch. Surg., Chicago, 5, 702, 1922.

10. Compere, E. L. and Adams, C. O.: Studies of longitudinal growth of long bones; the influence of trauma to the diaphysis. J. Bone and Joint Surg., 19, 922, 1937.

11. David, V.C.: Shortening and compensatory overgrowth following fractures of the femur in children. Arch. Surg., \%, 438, 1924.

12. Emnens, H.: Stimulation of growth in length after humerus fractures in children. Acta 
orthop. scand., 26, 324, 1957.

13. Ferguson, A. B. : Surgical siimulation of bone growth by a procedure. J. Amer. med. Ass., 100, 26, 1933.

14. Gandhi, R. K., Wilson, P., Mason Brown, J. J. and Macleod, W. : Spontaneous correction of deformity following fractures of the forearm in children. Brit. J. Surg., 219, 5, 1962.

15. Greville, N. R. And Janes, J. M. : An experimental study of overgrowth after fractures. Surg. Gynec. Obstet., 105, 717, 1957.

16. Hass, S. L. : Stimulation of bone growth. Am. J. Surg. , 95, 125, 1958.

17. Hedberg, E. : Femoral fractures in children. Some view points on their prognosis and treatment. Acta chir. scand., 90, 568, 1944-1945.

18. Herndon, C. H. and Spencer, G. E. : An experimental attempt to stimulate linear growth of long bones in rabbits. J. Bone and Joint Surg., 35- $A$, 758, 1953.

19. Hiertoun, T. : Arteriovenous anastomoses and acceleration of bone growth. Acta orthop. scand., 26, 322, 1957.

20. Hınz, R. : Röntgenologische Untersuchungen über Callus und Knochenumbau deform geheilter Frakturen. Arch. klin. Chir., 161, 49, 1930.

21. Hughston, J. C. : Fractures of the femur in children. I. A. S., 111, 180, 1960.

22. Hutchinson, W. J. and Burdeaux, B. D. : The influence of siasis on bone growth. Surg. Gynec. Obstet., 99, 413, 1954.

23. Inove, H. : Clinical observation of effect of longitudinal growth following fraciures of growing long bones. J. Kurume Med. Ass., 22, 519, 1959.

24. Jansen, K. and Langenskiöld, A. : Inhibition and stimulation of growth. Acta orthop. scand., 26, 296, 1957.

25. Kieling. : Röntgenologische Síudien über den Knochenabbau bei Frakturheilung. Arch. orthop. Chir., 25, 395, 1927.

26. KöNı,,F. : Die späteren Schicksale deform geheilter Knochenbruche, bəsonders bei Kindern. Arch. klin. Chir., 85, 187, 1908.

27. KöNıG, F. : Über Abbau am gebrochenen Knochen, s:in Wesen und sæine Bedeutung. Arch. klin. Chir., 146, 624, 1927.

28. Levander, G. : Über die Behandlung von Brüchen des Oberschenkelschaftes, nebst Beitrag zur Kenninis des gesteigerten Langenwachstums der röhren Knochen der unteren Extremitäten nach Bruch derselben. Zbl. Chir., 32, 20ミ0, 1930.

29. Murayama, T. : Cinical observation on spontaneous correction of fracture of the shaft of growing long bone. J. Kurume Med. Ass., 26, 256, 1963.

30. Schlotherm. : Über Callusbildung auf Grund systematischer Röntgen-aufnahmen bei heilenden Knochenbrüchen. Disch. Z. Chir., 144, 289, 1918.

31. Speed, K.: Longitudinal overgrowth of long bones. Surg. Gynec. Obstet., 36, 787, 1923.

32. StahL, F. : Plugging of the marrow cavity of the tibia for stimulation growth in length. Acta orthop. scand., 26, 322, 1957.

33. Truesdeld, E. D. : Inequality of the lower extremities following fractures of the shaft of the femur in children. Ann. Surg., 74, 498, 1921.

34. Trueta, J.: The influerce of the blood supply in controlling bone growth. Surg. 'Gyne. Obstet., 100, 179, 1955.

35. Wray, J. B. : Goodman, H. O. : Post fracture vascular phenomena and long bone overgrowth in the immature skeleton of the rat. J. Bone and Joint Surg. , 43-A, 1047, 1961.

36. Wu, Y. K. and Mitmer, L. J.: A procedure for stimulation of longitudinal growth of bone. J. Bone and Joint Surg., 19, 909, 1937. 